\title{
Virtual Currencies Like Bitcoin As A Paradigm Shift In The Field Of Transactions
}

Chris Richter, Lappeenranta University of Technology, Finland Sascha Kraus, University of Liechtenstein, Liechtenstein Ricarda B. Bouncken, University of Bayreuth, Germany

\begin{abstract}
Virtual currencies have been well-cited and well-discussed in the near past. Due to the loss of trust in the banking sector and the fear of loss of capital, low interest rates and uncertainty of existing currencies, the ground for a virtual currency was given. Virtual currencies and the money flows are controlled only online by the anonymous group of volunteers (also called peer); every single transaction is documented. Approximately 10,000 businesses worldwide accept payments with virtual currencies already, and the number is increasing steadily. This article analyzes the advantages and disadvantages of virtual currencies in comparison to real money and gives an outlook to a new banking system with high transparency and the chance to lead to a paradigm shift in the world of transactions and banking.
\end{abstract}

Keywords: Virtual Currencies; Bitcoin Advantages and Disadvantages; Outlook; Future

\section{INTRODUCTION}

ince the crisis in the banking sector starting in 2008, a strong loss of trust has been noticed (Roth, 2009). Loss of capital, historically low interest rates for savings and uncertainty over the future of the euro supported a transformation in traditional thinking. Citizens began to question the conventional banking system as they started to think about a new currency, independent from the old system. This currency was supposed to have advantages that traditional currencies do not have. Virtual, digital currencies were born and developed. Virtual currencies are based on the Internet, which has been steadily growing since the launch for public use in 1996. The opportunity to participate in the digital world increases day by day. So far around 2.4 billion people have daily access to the world wide web (Statista, 2014c) out of 7.2 billion ( Stiftung Weltbevölkerung, 2014), roughly calculated 35 per cent.

Considering the economic power of the Internet, constant growth has to be considered. The total worldwide (Business-to-Consumer; B-2-C) e-commerce turnover was around 1.248 billion US dollars in 2013. A doubling of this turnover is predicted for 2017 already (Statista, 2014b). In order to emphasize these figures correctly, they amount to as much as the combined turnover of the three world-leading companies Royal Dutch Shell, ExxonMobil and Walmart per year (Fortune, 2014). The Internet stands for "always on", purchasing 24/7, quick deals, individual responsibility, limited control by authorities and a high degree of anonymity (Rennhard \& Plattner, 2002). These characteristics have also been combined with the new phenomenon which occurred for the first time in $2009-$ "virtual currencies" (VC; sometimes also called "cryptocurrencies"). VC implies math-based peer-to-peer digital currencies that have no central administrating authority and no central monitoring or oversight (FATF Report, 2014). Currently, there are more than 270 different VC in use, and the number is increasing steadily. bitcoin is the most prominent one (Turpin, 2014); others include Litecoin or Ripple (Middlebrook \& Hughes, 2014).

Looking at the headlines of highly-accepted business magazines and newspapers in the summer of 2014, the phenomenon of VC, and here especially the "bitcoin", is much written about. The US multinational Dell, the third-largest PC manufacturer, accepts bitcoin payments for purchases since July 2014, shortly followed by Apple, Cisco, Adidas, Starwood Hotels and Toyota (Tech Times, 2014). Almost 10,000 companies worldwide accept payments in the digital form at the moment, with numbers increasing. 
On the other hand, the European Central Bank (2012) advises against the use of VC.

The renowned Massachusetts Institute of Technology (MIT) has released a public press statement which presents a novel approach for the implementation of a digital currency system in the upcoming winter term 2014. Two students have raised $\$ 500,000$ funding, because giving "students the access to VC (cryptocurrencies) is analogous to providing them with internet access at the dawn of the internet era". Every undergraduate student will receive a certain amount of bitcoin at the start of the winter term for free disposal. This project will be monitored scientifically, in particular in the question of possible fields of use, internal rules of the exchange, and innovation (Crudele, 2014).

Bitcoin was created by Satoshi Nakamoto in 2008 (Meiklejohn et al., 2013). It is a decentral currency with a peer-to-peer network and control system; the amount of bitcoin is limited to 21 billion (Reid \& Harrigan, 2013). This is an alternative to central banking with a control system of bankers and governments. In the early days of this currency, two options to get bitcoin were provided. The first one was so-called "mining", another word for calculating digital operations (Kroll, Davey, \& Felten, 2013). Highly modern, powerful computers are necessary to produce bitcoin through mining. The second option is to buy bitcoin through an exchange of "real" money. Every single bitcoin is coded with cryptographic protection and every single transaction is protocolled and supervised by the group of volunteers (peer-to-peer protocol for witnessing settlements; Meiklejohn et al., 2013). This means a more or less private and anonymous transfer of money is possible. No old-school banks are part of these transactions, and its flow is globally visible. A reduction of transaction costs is the result.

VC transactions are growing, but are still at a rather low level. At the moment, the number of transactions daily is estimated at 100,000 in comparison to approximately 295 billion transactions in the classic banking procedure (European Central Bank, 2012).

This paper aims at building a first scientific overview on the emerging topic of $\mathrm{VC}$ with special scope on their opportunities and challenges by means of a detailed review of the extant academic literature on the topic from 2000 to 2014. Since VC are an interdisciplinary approach, business and management journals were taken into account along with works on IT, law, innovation, entrepreneurship and economics. Additional studies cited by these works are incorporated into this article. A database search using the Thomson Reuters Web of Knowledge and leading electronic databases (EBSCO, EconLit, Business Source Premier, Academic Search Premier, Science Direct and Emerald Management Xtra) located usable texts. The selected journals were identified based on certain key words (including $\mathrm{VC}$ or bitcoin) in their titles and/or abstracts.

\section{LITERATURE REVIEW}

The field of VC is very young, with the first publications only appearing in the early 2000 s, mostly based on theoretical models. These models showed a potential way to create an innovative VC, but they did not analyze concrete parameters due to a lack of existing models and currencies (Buttyan \& Hubaux, 2001; Irwin, Chase, Grit, \& Yumerefendi, 2005). A large number of publications in the field of currencies in the video gaming industry appeared in the early 2000s, partly named "synthetic worlds" (otherwise known as virtual worlds or MMORPGs, which stands for Massively Multiplayer Online Role-Playing Games; Malaby, 2006). These phenomena are based on intense gaming and earning rewards in a second, virtual surrounding. Examples are the games "WorldWar" or "Second Life". Besides earned virtual income through finishing tasks or selling components in the game, a second option was born: spending real money to expand the experience of the video game. In this way, it is possible to spend real US dollars (for example) to get better equipment, more game levels or a faster speed connection for the game, which has been called "EBaying" (Yamaguchi, 2003). The revenues of the gaming industry are growing constantly (Repetti \& Jung, 2013) mainly due to the described phenomena. This development of bringing together real world with the virtual world of videogames is assumed as the starting point of the idea of VC with payment options for real goods. It followed a movement by authors writing about developments of VC in the gaming industry and overviews of common VC (Peng \& Sun, 2009; Guo \& Chow, 2008; Guo \& Gong, 2011). An innovation was born in 2008 with the publication of Satoshi Nakamoto about "bitcoin", when it was announced they would be introduced to the markets in 2009 (Nakamoto, 2008). The author described the development of the currencies and 
opens the view to market followers. This article is hard to follow for non-IT experts, but is considered as the starting point for the $\mathrm{VC}$ movement.

At the same time, Guo and Chow (2008) identified five central challenges for VC: (a) security threat, (b) danger of virtual money system collapse, (c) impacts of real-world monetary systems, (d) money laundering, tax evasion and online criminal and finally (e) value fluctuation of virtual money. These five identified challenges are the basis for most of the later developed articles and will be the groundwork for the discussion of advantages and disadvantages in this article as well (see figure 1).

Figure 1. Challenges For Virtual Currencies (Guo \& Chow, 2008)

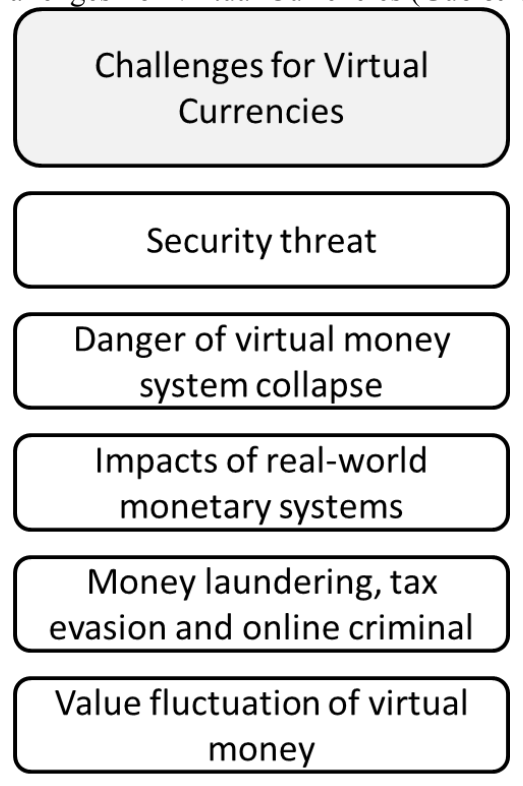

After the first years of use, scholarly articles have opened up their viewing angle dramatically. Earlier, it was more the idea and the vision of $\mathrm{VC}$, so now followed very specific and intensive observation of $\mathrm{VC}$ in various scientific directions, such as the addition of VC for companies as a loyalty instrument (Buchinger, Ranaivoson, \& Ballon, 2013), safety regulations (Bamert, Decker, Elsen, Wattenhofer, \& Welten, 2013), profit-driven abuses (Huang, 2013), overall regulation (Ly, 2014), innovation in the financial transaction world (Villasenor, Monk, \& Bronk, 2011), the legal status (Bollen, 2013), challenges in the taxation (Bal, 2013) and exchange rates (Guo \& Xie, 2013). The number of articles has been steadily growing, showing the increased level of attention on VC. So far, there is no consistent and commonly agreed-upon definition of what a $\mathrm{VC}$ is, mainly due to these different scientific fields which have their different angles. Besides the field of innovation, IT (technical requirements), law (treatment of this peer-to-peer currency) and economy (money, prices, volatility) are touched upon, which makes it more complex. Figure 2 shows the complex construction of classification for $\mathrm{VC}$ in the world of science.

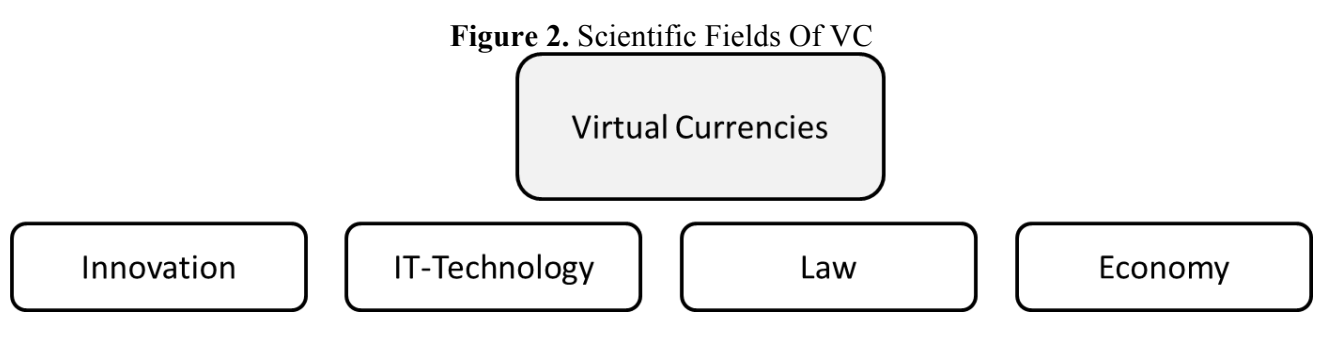

Below, an overview of the most-cited definitions of $\mathrm{VC}$ is given as well as two descriptions of a concrete example (bitcoin) to make it more tangible (see table 1). 
Table 1. Definitions Of VC And Bitcoin

\begin{tabular}{|c|c|c|c|c|}
\hline \multicolumn{5}{|c|}{4 Definitions Of VC And Bitcoin } \\
\hline$\#$ & Focus & Name Author & Year & Definition \\
\hline 1 & $\mathrm{VC}$ & $\begin{array}{l}\text { GAO } \\
\text { United States } \\
\text { Government } \\
\text { Accountability Office, } \\
\text { Report to the } \\
\text { Committee on Finance, } \\
\text { U.S. Senate on } \\
\text { "Virtual Economies and } \\
\text { Currencies" }\end{array}$ & 2013 & $\begin{array}{l}\text { "There are no legal definitions for a virtual currency. A } \\
\text { virtual currency is, generally, a digital unit of exchange that } \\
\text { is not backed by a government-issued legal tender." }\end{array}$ \\
\hline 2 & $\mathrm{VC}$ & European Central Bank & 2012 & $\begin{array}{l}\text { "A virtual currency is a type of unregulated, digital money, } \\
\text { which is issued and usually controlled by its developers, and } \\
\text { used and accepted among the members of a specific virtual } \\
\text { community." }\end{array}$ \\
\hline 3 & bitcoin & Ateniese & 2014 & $\begin{array}{l}\text { "bitcoin is a peer-to-peer ( } \mathrm{p} 2 \mathrm{p} \text { ) electronic cash system that } \\
\text { uses a distributed timestamp service to record transactions in } \\
\text { a public ledger (called the Blockchain). A critical } \\
\text { component of bitcoin's success is the decentralized nature of } \\
\text { its architecture, which does not require or even support the } \\
\text { establishment of trusted authorities." }\end{array}$ \\
\hline 4 & bitcoin & Nakamoto & 2008 & $\begin{array}{l}\text { "bitcoin is a digital, decentralized, partially anonymous } \\
\text { currency, not backed by any government or other legal } \\
\text { entity, and not redeemable for gold or other commodity. It } \\
\text { relies on peer-to-peer networking and cryptography to } \\
\text { maintain its integrity." }\end{array}$ \\
\hline
\end{tabular}

There is a fixed supply of 21 million bitcoin and no monetary or governmental authority has the right to create bitcoin. Only the integrated peer group, so-called "miners", create bitcoin and have the responsibility for the currency and the trades. The miners control every single transaction through a public ledger system, known as the block chain, that validates every single transaction (Deloitte, 2014). In comparison to real currencies (e.g. US dollar or euro), the control factor is given by the peer group, meaning less central orientation and lower transaction costs.

\section{Fields Of Application}

After the literature review and a selection of common definitions, the following section deals with different kinds of $\mathrm{VC}$ and builds the basis for the upcoming discussion of advantages and disadvantages of $\mathrm{VC}$. A short description of a use in the real world closes this section.

Three different types of VC are known and accepted. These are shown in Figure 3. They are based on the observation of the European Central Bank (2012) and are discussed by scientists.

Figure 3. Different Types Of VC (European Central Bank, 2012)

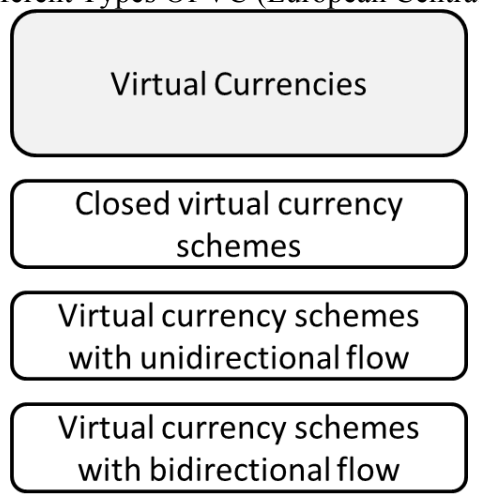


Each type will be discussed briefly and enriched by real-world experiences.

\section{Closed Virtual Currency Schemes}

This kind of currency has almost no link to the "real" world and is mostly used in online games (KPMG, 2013). Virtual money is earned solely by online performance. This kind is also called "in-world money" (Guo \& Chow, 2008) because it measures in-world consumption, in-world production, in-world investments, in-world services, and even in-world virtual government spending. No exchange or purchases outside the specific virtual community (e.g. one specific game) is possible. A trade between two different virtual worlds (e.g. two different games) is not possible; the consequence is "non-transferability" (Guo \& Chow, 2008). Selling or using the online currency in the real world is strictly forbidden. An earlier, concrete example of a closed system in online games are the gold coins of Ultima Online (Dibbel, 2006). Another example is World of Warcraft (WoW) Gold (de Jong, 2013).

\section{Virtual Currency Schemes With Unidirectional Flow}

VC can be purchased with "real money" (e.g. dollar, euro, yen) at a specific exchange rate. A back-to-back exchange is not possible. Examples of purchases are spending on virtual goods or services again, but sometimes real goods and real services can be purchased as well (European Central Bank, 2012). The video gaming company Nintendo introduced so-called Nintendo Points. Customers could buy these points with credit card payments or by purchasing Nintendo cards in retail stores (comparable with pre-paid cellphone cards or Apple iTunes vouchers). The Nintendo points could be used online and offline: online in several games for better equipment or levels, offline for purchasing goods in Nintendo stores. Further examples are the former Facebook Credits (now discontinued credits to buy virtual goods and services within Facebook), Amazon Coins (which Kindle users can exchange real money for and then use to buy applications), or frequent-flyer points like Miles and More from Lufthansa, Project Entropia Dollars or Q Coins (FATF Report, 2014).

\section{Virtual Currency Schemes With Bidirectional Flow}

Users can buy, sell or exchange virtual money, always related to the exchange rate. Therefore, the VC are comparable with any other real currency and can be used for purchases online and offline (European Central Bank, 2012). The best known example are the Second Life Linden Dollars (L\$), which could be used to customize the video game character and could be purchased with US dollars and other currencies. Through the illustration of the true life in the video game, it was possible to gain wealth (e.g. selling goods or services, savings) and transfer the amount back into US dollars. Already in 2011, the American company SEE Virtual Worlds bought a virtual planet called "Calypso" in a MMO online game for six million US dollars. The MMO was established in 2003 and has more than 950,000 users (Buffed.de, 2014). The video game developer Arkadia Studios from Singapore offered their customers virtual real estate in their game "Entropia Universe", the world's largest online multiplayer game with a real money economy (Deutsche Wirtschafts Nachrichten, 2014). This shows that new VC use this option to transfer money in the online world and allow purchases in the real world.

\section{Challenges Of Virtual Currencies}

The following section will discuss advantages and disadvantages with an exclusive scope on virtual currency schemes with bidirectional flow due to its greatest relevance for the public.

In general, all businesses are able to use $\mathrm{VC}$ comparable with electronic payment services like credit card systems (e.g. VISA, Mastercard) or cash transactions. There are no official limitations, restrictions or regulations known (compare PWC, 2014). By now, approximately 10,000 businesses worldwide accept payments with VC. This number is increasing steadily, because it is very easy to participate. Professional add-ins for companies' websites are available to expand the payment options for customers without high efforts and costs; it is comparable to adding Google maps to the website or the option to pay by credit card (Handelsbaltt, 2014). 
The literature lists six main advantages of VC:

World-Wide Toll-Free Transfers

In the established banking world, individual transactions from " $\mathrm{A}$ " to "B" are usually connected with fees, depending on the complexity and the internationality. Flatrates or individual feeds are differentiated between. Transactions are toll-free and especially interesting for foreign transactions (Reid \& Harrigan, 2013).

\section{No Possibility Of Censorship Or Blocking}

This aspect is especially interesting for areas with political or economic turbulences (Brezo \& Bringas, 2012). In the very near past, the European Union has frozen many accounts of Russian citizens and even Russian companies due to the perceived misbehavior of President Putin in a political conflict with the Ukraine (The Wall Street Journal, 2014).

No Inflation

Due to the fixed number of bitcoin, a devaluation of the currency cannot occur in terms of the classical multi-production of money. This is based on the planned number of 21 million bitcoin which form the basis of the system. Only supply and demand influence the value of bitcoin (Meiklejohn et al., 2013).

\section{Transaction Time}

Several scientists could find options to secure a fast transaction time. Changes in the process make it possible to use VC even at fast food restaurants (Karame, Androulaki, \& Capkun, 2012) or snack machines (Bamert et al., 2013). This is characteristic of the next stage in the developing process of $\mathrm{VC}$ and needs to be integrated in the common transaction process.

\section{Transparency/Tamper Resistant}

The system is initially easy to understand in contrast to the real-world practice of money creation. There are an established number of bitcoin available; the value is based on supply and demand and so reacts with fluctuations in value. All information is known, making it transparent. Also fraud with fake money is excluded, but this needs to be analyzed in more detail in the future (Barber, Boyen, Shi, \& Uzun, 2012).

\section{Sustainability}

One very "hot" current trend in the economic system consists of the ambition to follow a product from endto-end. This implies knowing where the individual components have their origin and whether they are ethically and morally on an acceptable level in the manufacturing sector. This requires a lot of effort for the companies (Closs, Speier, \& Meacham, 2011). In the case of virtual currency this traceability is given, but under the cloak of anonymity. The original approach of sustainability (social, economic and ecological) is not touched here.

A collection of the most relevant challenges and points of discussion on $\mathrm{VC}$ follow. It is based on the already introduced five fields of challenges by ECB and is enriched by various aspects. The missing acceptance in the broad publicity stands out; the missing faith is explained through misbehavior in the near past, e.g. Mt Gox and the mostly negative public relation.

\section{Acceptance/Faith}

The main challenge for innovation in general is a lack of acceptance in the broad public. Users of VC are often considered to be "IT hackers". The lack of acceptance by governments, banks or the economy is mostly based on the fear of losing control and with the loss of control the loss of money and the business model (Darlington III, 
2014). Venture capital is given to start-ups operating in the field of VC, e.g. the former Facebook founder and the Winklevoos twins invested a large amount (Ly, 2014). Venture capital stands in for challenges, for risk-taking and for innovativeness, but on the other hand for opportunities, creating creative solutions and openness. The acceptance has suffered greatly, mostly as a result of the following aspects.

\section{Money Laundering, Tax Evasion And Online Criminal}

VC are created by either virtual money creation rules or through mining (Guo \& Gong, 2011). The threat of an intervention by hackers exists; they could produce money for themselves or change the amount of their credit. The credibility, especially in terms of flawlessness and correctness, is not given in its entirety (Hanley, 2013). Illegal access to existing accounts of VC is extensively documented. The most spectacular case was in 2014, where hackers used a hole in the security system to change transactions between the peers; approximately 100 cases are known with irregularities at various digital stock exchanges (eRecht24, 2014). Money laundering is mentioned frequently; scientists prove this concept wrong due to the perceived anonymity of the user. But this is a limited anonymity; the transactions within the virtual world are all documented and every user is identified by a string. The access or the entrance into the $\mathrm{VC}$ is the bottleneck, since the user needs an official bank account to transfer money into the system. As long as this procedure is controlled by authorities, the option of crimes is limited dramatically. The banking program "Know your customer", which requires true identities and residences of account holders, gets an even higher priority (Barnett, 2014). Tax evasion is more relevant due to a lack of regulations, laws and control systems. Arbitrage earnings through exchange rate fluctuations can be considered as a separate business model due to the extremely high volatility. Taxes for these gains are currently not implemented because most governments have not recognized this gap yet, and no laws are on the way yet either.

\section{Limited Group Of Users}

The limited group of users makes it suspicious in different ways. The business model is created to gain wealth for the founder, in the case of bitcoin a group of unknown persons. bitcoin are currently used by approximately 130,000 users, and only a small group has a higher number of bitcoin and the transactions are limited so far (Statista, 2014a). There is a risk of arbitrariness of the founders, comparable with the virtual money in the online game World of Warcraft, where users could buy virtual real estate for real money and were expropriated by the founders. Due to the limitation of central authorities there was no deposit guarantee (Andrychowicz, Dziembowski, Malinoswki, \& Mazurek, 2013).

\section{Value Fluctuation Of Virtual Money}

Value fluctuation is an obvious challenge of virtual money due to the limited use of transactions (as mentioned above, only approximately 100,000 transactions with VC are completed each day in comparison to 295 billion with real money). The typical challenge of supply and demand of currencies is also known by less important currencies (e.g. Brazilian Real or Turkish Lira) in the real world, but it is not comparable with the euro or the Swiss franc or even gold (Yermack, 2013).

\section{Impacts Of Real-World Monetary Systems}

An independent currency not controlled by states or groups of states leads to uncertainty, though it is an innovation. The direct access and possible regulation of the highest instances falls away, and the new central instance is the peer-to-peer collective. This means the power of banks and governments could be limited in the future (Stiller et al., 2014). Right now, the impact of VC in the world trade is small, but steadily growing. It is believed that $\mathrm{VC}$ are an extension of the existing payment options such as cash, credit cards or the exchange of services. Due to the rising importance of digitalization, the percentage of trades is predicted to be strongly increasing. 


\section{Danger Of Virtual Money System Collapse}

The danger of a collapse of VC and their exchange is justified and was confirmed lately in spring 2014 with the end of the until then most known and most used exchange point Mt. Gox, which was marked by irregularities and inaccuracies (Barnett, 2014). More than $60 \%$ of the bitcoin trading volume was provided by Mt. Gox before they stopped the exchange of bitcoin and then took their website offline and filed for insolvency. The consequences were serious; allegedly more than 800,000 bitcoin were lost to hackers. This theory is strongly challenged by various scientists, who have determined that only about 400 bitcoin affected by the hacker attack may be lost (Heisse.de, 2014). So Mt Gox appears in an even worse light as the former main trading center and has damaged the confidence in bitcoin in the long term.

2.

Summarizing, the advantages and disadvantages of virtual currencies seem to be balanced, please see Table

Table 2. Overview Of Advantages And Disadvantages Of VC

\begin{tabular}{ll}
\hline \multicolumn{1}{c}{ Advantages } & \multicolumn{1}{c}{ Disadvantages } \\
\hline a. World-wide toll-free transfers and lower fees in general & a. Acceptance / faith \\
b. No possibility of censorship or blocking & b. Money laundering, tax evasion and online criminal \\
c. No inflation & c. Limited group of users \\
d. Faster transactions & d. Value fluctuation of virtual money \\
e. Transparency / tamper resistant & e. Impacts of real-world monetary systems \\
f. Sustainability & f. Danger of virtual money system collapse \\
\hline
\end{tabular}

Bitcoin in particular and VC in general were predicted short product life cycles due to the challenges and disadvantages presented above. But that gives them the same starting point as, for example, driverless cars, unmanned drones and touchscreens (Floridi, 2014). The idea of a decentral peer-proved currency concept seems very interesting, the implementation in the near future and the challenge to be a new competitor on the established banking market will be very challenging.

The basis is built: the first million users are already working with bitcoin, and established companies like Dell, Apple and Adidas have started to accept this new currency.

\section{CONCLUSION}

This short overview about the steadily growing importance of VC with a scope on advantages and disadvantages shows the relevance of this topic.

The enormous presence in online and offline newspapers, magazines and other media underlines the increasing relevance of the topic. Current disadvantages are mostly known through the mismanagement of Mt. Gox - other national bitcoin exchanges perform without issues and work strongly on better performances and greater user security. The threat of fraud is given, especially in the virtual IT field, where a complete understanding of the background and the methods by every consumer is not realistic.

Considering the advantages, a solid basis for a new, influential kind of payment is given: a decentral power, based on mathematics. The merging of advantages could build the basis of a great innovation in the banking field. Currently, doubters are mostly found in the field of bankers and governments, which may fear a loss of their power. Giving an outlook to bitcoin and VC, the creator of bitcoin wrote something remarkable (Bitcoin, 2014):

bitcoin is an experimental new currency, and is actively developed. Although it is always less experimental with increasing use, you should be aware that bitcoin is a new invention, which explores the ideas that were previously never tried. Therefore, the future can be predicted by anyone.

This article accepts the important position in the scientific field and underlines the existing basis for a novel, highly relevant innovation in the financial services sector. Transparency and traceability of cash flows and thus sustainability are central themes in 2014. The broad confidence in banks is damaged, so there is enough space 
for a new, functional currency. Therefore, the authors of this article predict $\mathrm{VC}$ to be a success story that might become comparable to the credit card penetration worldwide. The advantages of $\mathrm{VC}$ are concrete and verifiable (e.g. faster, encrypted, cheaper). The disadvantages are mostly soft facts like a lack of trust, lack of acceptance, or a general fear of the new, fear of a collapse of the existing system.

The acceptance and the faith in this new currency could increase immediately with an official, central authority in the lead. It could be a newly created World Bank with all rights and duties, the change to be controlled by the peer-to-peer group, but with the security of no irregularities and inaccuracies. Considering the limitations of this work, the youngness of the field and the lack of experiences need to be stated. The existing literature is spread over different fields of science, so only a limited number of works exist and these are sometimes not comparable as a result of different backgrounds. This article is one of the first in which advantages and disadvantages are listed in a scientific way, using current sources from the academic world as well as from other sources. The overview of advantages and disadvantages can serve as a first step to delivering a more detailed picture of the field in the future. Another limitation is the strong focus on criminal aspects of VC due to the events at Mt. Gox, which makes it difficult to consider it in a neutral position.

Future research should be undertaken in a timely manner to understand the phenomenon better. Empirical work is necessary to understand the points of view of companies and end users better, and to understand what the real advantages and disadvantages are in the eyes of potential users. Interesting could also be the analysis of influencing factors, priorities and correlations between objective data and values (e.g. revenues, earnings and growth of the number of employees) of companies using VC. Another interesting research question would be the empirical study of fraud per transaction and comparing the trend of bitcoin on stock markets in comparison to real-world currencies like the US dollar or the euro.

A new era of transactions and banking has already started. The transparency of virtual currencies will change the business world dramatically.

\section{AUTHOR INFORMATION}

Chris Richter is a Ph.D. Student at the School of Business, Lappeenranta University of Technology, Finland. His research is focused on the fields of Entrepreneurship as well as entrepreneurial marketing. He already published articles about Smart Cities, Entrepreneurial Orientation, Shareconomy and Crowdfunding. Email: chris.richter@lut.fi.

Sascha Kraus is a Professor for Entrepreneurship at the University of Liechtenstein and a Visiting Professor at Copenhagen Business School, Denmark. He is also an Adjunct Professor at Lappeenranta University of Technology, Finland. Email: sascha.kraus@unisg.ch.

Ricarda Bouncken is Chair Professor of Strategy and Organization at the University of Bayreuth, Germany. Her research centers on diversity, innovation, and collaboration. Email: bouncken@uni-bayreuth.de. (Corresponding author)

\section{REFERENCES}

Andrychowicz, M., Dziembowski, S., Malinoswki, D., \& Mazurek, L. (2013). Fair Two-Party Computations via Bitcoin Deposits? IACR Cryptology ePrint Archive, 837.

Ateniese, G., Faonio, A., Magri, B., \& de Medeiros, B. (2014). Certified bitcoins. Paper presented at the Applied Cryptography and Network Security.

Bal, A. . (2013). Stateless Virtual Money in the Tax System. European Taxation, 7, 351-356.

Bamert, T., Decker, C., Elsen, L., Wattenhofer, R., \& Welten, S. (2013). Have a snack, pay with bitcoins. . Paper presented at the 2013 IEEE Thirteenth International Conference.

Barber, S., Boyen, X., Shi, E., \& Uzun, E. . (2012). Bitter to better-how to make bitcoin a better currency Financial Cryptography and Data Security (pp. 399-414): Springer Berlin Heidelberg.

Barnett, E. R. (2014). Virtual Currencies: Safe for Business and Consumers or just for Criminals? Paper presented 
at the 13 th European Security Conference \& Exhibition

Bitcoin. (2014). Some things you need to know. Retrieved 01.09.2014, from https://bitcoin.org/en/you-need-toknow

Bollen, R. . (2013). The Legal Status of Online Currencies: Are Bitcoins the Future? Journal of Banking and Finance Law and Practice, 1-38.

Brezo, F.G., \& Bringas, P. (2012). Issues and Risks Associated with Cryptocurrencies such as Bitcoin. Paper presented at the International Conference on Social Eco-Informatics.

Buchinger, U., Ranaivoson, H., \& Ballon, P. (2013). From Loyalty Points to Virtual Currencies: Expanding Loyalty Schemes for Mobile Platforms. Paper presented at the International Conference on Mobile Business Paper 9.

Buffed.de. (2014). Guinness Weltrekord: Teuerster Kauf eines virtuellen Besitztums für 6 Millionen US-Dollar. Retrieved 31.08.2014, from http://www.buffed.de/Planet-Michael-PC-235950/News/Guinness-WeltrekordTeuerster-Kauf-eines-virtuellen-Besitztums-fuer-6-Millionen-US-Dollar-819238/

Buttyan, L., \& Hubaux, J. P. (2001). Nuglets: a virtual currency to stimulate cooperation in self-organized mobile ad hoc networks

Closs, D. J., Speier, C., \& Meacham, N. (2011). Sustainability to support end-to-end value chains: the role of supply chain management. Journal of the Academy of Marketing Science, 39(1), 101-116.

Crudele, J. (2014). MIT students engineering bitcoin scheme. 30.08.2014, from http://nypost.com/2014/08/28/mitstudents-engineering-bitcoin-scheme/

Darlington III, J.K. (2014). The Future of Bitcoin: Mapping the Global Adoption of World's Largest Cryptocurrency Through Benefit Analysis. University of Tennessee, Knoxville.

de Jong, I. (2013). Overview of virtual currency schemes. Paper presented at the The World Bank - Global Forum on Law, Justice and Development, Washington D.C.

Deloitte. (2014). The new gold rush.

Deutsche Wirtschafts Nachrichten. (2014). Spiele-Entwickler verkauft virtuelles Grundstück für eine Million Dollar Retrieved 31.08.2014, from http://deutsche-wirtschafts-nachrichten.de/2014/03/31/spiele-entwicklerverkauft-virtuelles-grundstueck-fuer-eine-million-dollar/

Dibbel, Julian. (2006). Play Money: Or, How I Quit My Day Job and Made Millions Trading Virtual Loot: Perseus Books.

eRecht24. (2014). IT Sicherheit: Internetkriminalität - Hacker legen virtuelle Wägung Bitcoin lahm. Retrieved 01.09.2014, from http://www.e-recht24.de/news/it-sicherheit/7833-internetkriminalitaet-hacker-legenvirtuelle-waehrung-bitcoin-lahm.html], http://www.taz.de/!134242/

European Central Bank. (2012). Virtual Currencies Schemes.

FATF Report. (2014). Virtual Currencies Key Definitions and Potential AML/CFT Risks. Paris: Financial Action Task Force on Money Laundering / OECD.

Floridi, L. . (2014). The Fourth Revolution: How the Infosphere is Reshaping Human Reality: Oxford University Press.

Fortune. (2014). Fortune 500 2014. Retrieved 30.08.-2014, from http://fortune.com/fortune500/

GAO, United States Government Accountability Office. (2013). Virtual economoes and currencies, Additional IRS Guidance Could Reduce Tax Compliance Risks.

Guo, J., \& Chow, A. (2008). Virtual money systems: a phenomenal analysis. Paper presented at the 10th IEEE Conference

Guo, J., \& Gong, Z. (2011). Measuring virtual wealth in virtual worlds. Information technology and management, $12(2), 121-135$.

Guo, J., \& Xie, M. (2013). Achieving Satisfied Virtual Exchange Rates through Multiple-Stage Virtual Money Supply. Paper presented at the International Conference on In Cyberworlds.

Handelsbaltt. (2014). Zahlen wir bei Ebay bald mit digitalem Geld? , 31.08.2014, from http://www.handelsblatt.com/unternehmen/it-medien/einfuehrung-von-bitcoins-zahlen-wir-bei-ebay-baldmit-digitalem-geld/10338526.html

Hanley, B. P. (2013). The False Premises and Promises of Bitcoin. arXiv preprint arXiv:1312.2048, 1-32.

Heisse.de. (2014). Studie stellt Verlust bei Mt. Gox in Zweifel. Retrieved 01.09.2014, from ttp://www.heise.de/newsticker/meldung/Studie-stellt-Bitcoin-Verlust-bei-Mt-Gox-in-Zweifel-2156255.html

Huang, D. Y. (2013). Profit-driven abuses of virtual currencies.

Irwin, D., Chase, J., Grit, L., \& Yumerefendi, A. . (2005). Self-recharging virtual currency. Paper presented at the 
ACM SIGCOMM workshop on Economics of peer-to-peer systems.

Karame, G., Androulaki, E., \& Capkun, S. . (2012). Two Bitcoins at the Price of One? Double-Spending Attacks on Fast Payments in Bitcoin. IACR Cryptology ePrint Archive, 1-17.

KPMG. (2013). Virtually Unregulated Countering Virtual Currency, Money Laundering in the 21st Century: KPMG.

Kroll, J. A., Davey, I. C., \& Felten, E. W. . (2013). The economics of Bitcoin mining, or Bitcoin in the presence of adversaries. Paper presented at the WEIS.

Ly, M. K. M. . (2014). Coining Bitcoin's" Legal-Bits": Examining the Regulatory Framework for Bitcoin and Virtual Currencies. Harv. J. Law \& Tec, 27(587-587).

Malaby, T. . (2006). Parlaying value capital in and beyond virtual worlds. Games and culture, 1(2), 141-162.

Meiklejohn, S., Pomarole, M., Jordan, G., Levchenko, K., McCoy, D., Voelker, G. M., \& Savage, S. . (2013). A fistful of bitcoins: characterizing payments among men with no names. Paper presented at the 2013 conference on Internet measurement conference

Middlebrook, S. T., \& Hughes, S. J. (2014). Regulating Cryptocurrencies in the United States: Current Issues and Future Directions. Wm. Mitchell Law Review, 40, 813-1158.

Nakamoto, S. . (2008). Bitcoin: A peer-to-peer electronic cash system. Consulted, 1(2012), 28.

Peng, H., \& Sun, Y. . (2009). Network virtual money evolution mode: moneyness, dynamics and trend. In Information and Automation. Paper presented at the International Conference Information and Automation, IEEE.

PWC. (2014). Virtual currencies: Out of the deep web, into the light. In r. Issues, and opportunities around the digitization of money (Ed.).

Reid, F., \& Harrigan, M. (2013). An analysis of anonymity in the bitcoin system. In Y. Altshuler, Y. Elovici, A. B. Cremers, N. Aharony \& A. Pentland (Eds.), Security and Privacy in Social Networks (pp. 197-223): Springer New York.

Rennhard, M., \& Plattner, B. (2002). MorphMix: Peer-to-Peer based Anonymous Internet Usage with Collusion Detection. Paper presented at the Privacy in the Electronic Society.

Repetti, T., \& Jung, S. (2013). Building the First Gaming Master's Program: An Industry Perspective. UNLV Gaming Research \& Review Journal, 17(2), 63-79.

Roth, F. (2009). The Effects of the Financial Crisis on Systemic Trust. Intereconomics, 44, 203-208.

Statista. (2014a). Anzahl der My Wallet-Benutzer in den Monaten November 2012 bis Juni 2014 (in 1.000). Retrieved 01.09.2014, from http://de.statista.com/statistik/daten/studie/283307/umfrage/anzahl-der-mywallet-benutzer/

Statista. (2014b). E-Commerce-Umsatz in Deutschland 1999 bis 2013 und Prognose für 2014 (in Milliarden Euro). Retrieved 30.08.2014, from http://de.statista.com/statistik/daten/studie/3979/umfrage/e-commerce-umsatzin-deutschland-seit-1999/

Statista. (2014c). Internetnutzer weltweit und nach ausgewählten Weltregionen in Millionen (Stand Juni 2012) Retrieved 30.08.2014, from http://de.statista.com/statistik/daten/studie/157868/umfrage/anzahl-derweltweiten-internetnutzer-nach-regionen/

Stiftung Weltbevölkerung. (2014). Datenreport 2014 - Soziale und deografische Daten weltweit. Hannover: Stiftung Weltbevölkerung.

Stiller, B., Schmitt, C., Garg, R., Bocek, T., Dönni, D., \& Machado, G. (2014). Internet Economics VIII. In T. R. N. IFI-2014.01 (Ed.): University of Zurich - Department of Informatics (IFI).

Tech Times. (2014). Consumer Financial Protection Bureau warns public of bitcoins, other virtual currencies.

The Wall Street Journal. (2014). Berlin Lays Groundwork with German Public for Stiffer Russian Sanctions. Retrieved 31.08.2014, from http://online.wsj.com/articles/berlin-lays-groundwork-with-german-public-forstiffer-russian-sanctions-1406482633

Turpin, J.B. (2014). Bitcoin: The Economic Case for a Global, Virtual Currency Operating in an Unexplored Legal Framework. Indiana Journal of Global Legal Studies, 21(1), 335-368.

Villasenor, J., Monk, C., \& Bronk, C. (2011). Shadowy Figures: Tracking Illicit Financial Transactions in the Murky World of Digital Currencies, Peer-to-peer Networks, and Mobile Device Payments.: Brookings Institution.

Yamaguchi, H. (2003). An analysis of virtual currencies in online games. The Japan Center for International Finance, 1-8.

Yermack, D. (2013). Is Bitcoin a Real Currency? National Bureau of Economic Research, (No. w19747). 


\section{NOTES}

